\title{
The Effect of Part-Time Work on Wages: Evidence from the Social Security Rules
}

\author{
Daniel Aaronson, Federal Reserve Bank of Chicago \\ Eric French, Federal Reserve Bank of Chicago
}

This article identifies the part-time wage effect, using hours variation caused by the social security rules. We show that work hours and wages drop sharply at ages 62 and 65 . We argue that the hours decline causes the wage decline, resulting in a $25 \%$ wage penalty for men who cut their work week from 40 to 20 hours. However, we find little evidence for such an effect among women. We also show that models that fail to account for the joint determination of hours and wages will understate the labor supply response to a tax change by about $26 \%$.

\section{Introduction}

Labor supply models typically assume that a worker receives a fixed wage offer and chooses the number of hours to work given that wage. However, the wage offered to workers may be determined by the number of hours worked by an employee. ${ }^{1}$

The purpose of this article is twofold. First, we show how taxes affect

We thank Kirti Kamboj and Ken Housinger for their great assistance and Dan Sullivan and Ruilin Zhou for helpful discussions. Our views do not necessarily reflect those of the Federal Reserve Bank of Chicago or the Federal Reserve System. Contact the corresponding author, Daniel Aaronson, at daaronson@frbchi.org.

${ }^{1}$ See Barzel (1973), Rosen (1976), Moffitt (1984), and Ermisch and Wright (1993) for descriptions of why wages may vary with hours worked.

[Journal of Labor Economics, 2004, vol. 22, no. 2]

(C) 2004 by The University of Chicago. All rights reserved.

0734-306X/2004/2202-0003\$10.00 
hours worked in a model where hours and wages are jointly determined. Standard labor supply elasticities measure the relationship between labor supply and the wage. Tax analysts use these estimated labor supply elasticities to predict the labor supply response to a tax change. However, tax analysts usually fail to account for the effect of hours worked on the wage. This failure creates a problem because a tax increase not only lowers the after-tax wage because of a change in the marginal tax rate but also indirectly lowers the pre-tax wage through the tax change's effect on hours worked. Therefore, failure to account for this latter effect leads to an underestimate of the effect of tax changes on the post-tax wage and consequently to an underestimate of the effect of tax changes on labor supply.

The second purpose of this article is to provide new estimates of the effect of work hours on the wage. In order to estimate the effect of hours worked on the wage, we must overcome an important identification problem. It is not clear whether changes in hours affect wages or whether changes in wages affect hours. Previous studies that try to measure the part-time wage effect often use an instrumental variables strategy that employs the number of young children in the household and other childbearing demographics as instruments for hours worked in samples of working women. ${ }^{2}$ Presumably, increases in the number of children cause reductions in a woman's work hours. Researchers interpret differences in wages between women with and without children as resulting from differences in work hours. However, this is a valid strategy only if young children reduce a mother's available time for work and do not directly affect her productivity. Furthermore, if young children also restrict the mother's job opportunities, perhaps because she needs a flexible work schedule, then her wages are lower not because she is a part-time worker but because she faces other work restrictions. This would lead to an overestimate of the effect of part-time work on wages. Nevertheless, examples using such instruments result in estimates of the part-time/fulltime wage differential that are all over the board. ${ }^{3}$

In order to identify the part-time wage differential, we take advantage of what we believe is a better instrument for hours worked, that is, the work disincentives of the social security system. At ages 62 and 65 , individuals face incentives to reduce their work hours. During our sample period, most individuals age 62 and older are eligible for social security benefits but face an earnings test until age 69 . Above the social security earnings test threshold level, individuals face a high marginal tax rate on

${ }^{2}$ Rosen (1976), Moffitt (1984), Simpson (1986), Blank (1990), Hotchkiss (1991), and Ermisch and Wright (1993) use this strategy. Lundberg (1985) finds that lagged hours has predictive ability for wages and argues that this predictive power is evidence in favor of tied wage-hours offers. We are aware of no other identification strategy.

${ }^{3}$ See Blank (1990) for a review. 
earnings. Between ages 62 and 64, benefits lost through the earnings test are replaced in the form of higher benefits in the future, resulting in about a dollar of higher benefits in present value in the future for every dollar lost through the earnings test. However, if individuals are liquidity constrained, it may not be until age 62, when the early retirement provision of the social security rules applies, that they will have sufficient financial resources to reduce their work hours. After age 65, benefits lost through the social security earnings test result in only small increases in future benefits. Therefore, the social security earnings test results in a strong incentive to reduce work hours by age $65 .^{4}$

A further reason the social security system provides incentives to reduce work hours by age 65 is that, for many workers, health insurance is included with their job. Many individuals who would reduce their work hours would also lose their health insurance, exposing them to the risk of facing health problems without insurance. At age 65, all individuals who are eligible for social security are also eligible for medicare. This means that most individuals who are age 65 and older have reasonable quality health insurance even if they lose their employer-provided insurance.

While we believe that our identification strategy is a useful addition to the literature, a disadvantage to this approach is that we are working with the oldest of workers. Therefore, our results are not necessarily representative of other populations of workers.

Nevertheless, using these instruments and data from the Health and Retirement Survey (HRS), the Panel Study of Income Dynamics (PSID), and the Current Population Survey (CPS), we find evidence that male part-time workers earn lower wages than male full-time workers. Depending on the specification and the data employed, our estimates imply that cutting hours from 40 to 20 hours per week lowers wages by as much as $25 \%$ for men. Many, but certainly not all, of our estimates are significant at the $10 \%$ level or higher, and point estimates are similar across the different data sets. The point estimates appear to be relatively robust to attempts to control for confounding factors that might influence changes in wages at ages 62 and 65 . However, the evidence for a parttime penalty among female workers is weak.

\section{Estimating the Intertemporal Elasticity of Substitution with Tied Wage-Hours Offers}

In this section, we present a standard life cycle labor supply model augmented to include tied wage-hours offers. Solving the model illumi-

${ }^{4}$ For formal evidence, see French (2000). 
nates a fundamental model misspecification problem. ${ }^{5}$ An increase in the posttax wage from a tax cut potentially leads to an increase in hours worked. Additionally, this increase in the work week leads to an increase in the pretax wage through the tied wage-hours effect, further increasing hours worked. Therefore, there is a larger labor supply response to a tax change than to an equally large wage change. Most models do not account for tied wage-hours offers and thus ignore this latter effect. Therefore, the model misspecification problem causes tax analysts to understate the labor supply response to a tax change.

\section{A. The Intertemporal Labor Supply Model}

We begin with the canonical intertemporal labor supply model, ${ }^{6}$ as in MaCurdy (1985), augmented to account for tied wage-hours offers. Preferences take the form:

$$
U=E_{0} \sum_{t=1}^{T} \beta^{t}\left[v\left(c_{i t}\right)-\exp \left(-\varepsilon_{i t} / \sigma\right) \times \frac{h_{i t}^{1+(1 / \sigma)}}{1+(1 / \sigma)}\right],
$$

where $U$ is the expected discounted present value of lifetime utility, $c_{i t}$ is consumption, $v($.$) is some increasing concave function, h_{i t}$ is hours worked, and $\varepsilon_{i t}$ is the person- and year-specific preference for work. The parameter $\sigma$ is the intertemporal elasticity of substitution, which is the usual object of interest in intertemporal labor supply studies. Define $A_{i t}$ as assets, $r_{t}$ as the interest rate, and $W_{i t}\left(\log h_{i t}\right)$ as the post-tax wage, which potentially depends on hours worked:

$$
\begin{gathered}
\log W_{i t}\left(\log h_{i t}\right)=\log w_{i t}\left(\log h_{i t}\right)+\log \left(1-\tau_{t}\right), \\
\log w_{i t}\left(\log h_{i t}\right)=\alpha_{i t}+\theta \log h_{i t},
\end{gathered}
$$

where $w_{i t}\left(\log h_{i t}\right)$ represents the pre-tax wage, $\alpha_{i t}$ represents an individual's underlying productivity or technology during a specific year, and $\tau_{t}$ is the tax rate. We assume that the tax rate depends on neither wages nor hours worked. The function $\theta \log h_{i t}$ maps work hours into the wage. In one of the few papers that provide a theoretical explanation for the existence of

\footnotetext{
${ }^{5}$ A potential simultaneous equation bias is also present since hours depend on wages and wages depend on hours worked. Given that an increase in hours results in an increase in the wage and an increase in the wage results in an increase in hours, the simultaneous equations bias results in an upward bias for the labor supply elasticity if the econometrician uses ordinary least squares. However, this bias is overcome when using the standard instrumental variables procedures.

${ }^{6}$ The key results from this section do not depend on whether the model is static or dynamic. However, the intertemporal model simplifies the analysis because it allows us to focus more on the substitution effect of a tax change. In static models and models with liquidity constraints, tax changes cause an additional change in the marginal utility of wealth.
} 
tied wage-hours offers, Barzel (1973) suggests that, at low levels of hours worked, an additional work hour increases the hourly wage because the fixed costs of work (such as time spent in training) are spread over a longer work week, that is, $\theta>0$.

Maximization of (1) subject to equations (2) and (3) and the dynamic budget constraint

$$
A_{i t+1}=\left(1+r_{t}\right)\left[A_{i t}+W_{i t}\left(\log h_{i t}\right) h_{i t}-c_{i t}\right]
$$

results in the labor supply function

$$
\log h_{i t}=\sigma \log \left[\frac{\partial W_{i t}\left(\log h_{i t}\right) h_{i t}}{\partial h_{i t}}\right]+\sigma \log \lambda_{i t}+\varepsilon_{i t},
$$

where $\lambda_{i t}$ is the marginal utility of wealth.

Taking a first-order Taylor's series approximation around the term $\log \left[1+\left(h_{i t} / W_{i t}\right)\left[\partial W_{i t}\left(\log h_{i t} / \partial h_{i t}\right)\right]\right.$,

$$
\begin{aligned}
\log \left[\frac{\partial W_{i t}\left(\log h_{i t}\right) h_{i t}}{\partial h_{i t}}\right] & =\log \left\{W_{i t}\left(\log h_{i t}\right)\left[1+\frac{h_{i t}}{W_{i t}} \frac{\partial W_{i t}\left(\log h_{i t}\right)}{\partial h_{i t}}\right]\right\} \\
& \approx\left[\log W_{i t}\left(\log h_{i t}\right)+\frac{\partial \log W_{i t}\left(\log h_{i t}\right)}{\partial \log b_{i t}}\right] .
\end{aligned}
$$

Noting that

$$
\frac{\partial \log W_{i t}\left(\log h_{i t}\right)}{\partial \log h_{i t}}=\theta
$$

and combining (5), (6), and (7) results in

$$
\log h_{i t}=\sigma\left[\log W_{i t}\left(\log h_{i t}\right)+\theta\right]+\sigma \log \lambda_{i t}+\varepsilon_{i t} .
$$

The term in square brackets, parameterized by $\sigma$, is the logarithm of the opportunity cost of time. The opportunity cost of time has two parts. The first part arises because of increased income from increases in hours worked, holding the wage fixed. The second part arises because of increased income from a higher hourly wage when the individual works more hours. If changes in hours of work do not change the wage, then $\theta=0$ and equation (8) becomes the standard estimating equation in intertemporal labor supply models.

${ }^{7}$ If $\theta>0$, then the budget set is not convex. However, eq. (5) still represents an equilibrium condition so long as $\theta \sigma<1$. This condition is satisfied for reasonable parameter values. 


\section{B. Biases Caused by Model Misspecification}

We are not the first to point out that the labor supply function must be augmented to account for the marginal effect of work hours on wages. ${ }^{8}$ However, we believe that we are the first to show analytically why failure to account for tied wage-hours offers will produce labor supply elasticities that are smaller than the elasticity of interest. We describe the difference below.

Wage changes affect hours changes in the following way:

$$
\frac{d \log h_{i t}}{d \log W_{i t}}=\sigma\left(1+\frac{d \log \lambda_{i t}}{d \log W_{i t}}\right)
$$

Assuming $\left(d \log \lambda_{i t}\right) /\left(d \log W_{i t}\right)=0,{ }^{9}$ the labor supply response to the wage change is

$$
\left.\frac{d \log h_{i t}}{d \log W_{i t}}\right|_{\lambda_{i t}}=\sigma
$$

Therefore, $\left.\left(d \log h_{i t} / d \log W_{i t}\right)\right|_{\lambda_{i t}}$ is an unbiased estimator of $\sigma .^{10}$

However, the parameter $\sigma$ is no longer of interest if wages are tied to hours worked. Macroeconomists are interested in the co-movement of hours and technology, $d \log h_{i t} / d \alpha_{i t}$. Tax analysts are interested in the effect of taxes on labor supply, $d \log h_{i t} /\left[d \log \left(1-\tau_{t}\right)\right]$. The labor supply response to both technology changes and tax changes is the same. For convenience, we consider the effect of a tax change on a change in hours:

$$
\frac{d \log h_{i t}}{d \log \left(1-\tau_{t}\right)}=\sigma\left(1+\theta \frac{d \log h_{i t}}{d \log \left(1-\tau_{t}\right)}+\frac{d \log \lambda_{i t}}{d \log \left(1-\tau_{t}\right)}\right) .
$$

${ }^{8}$ Rosen (1976), Moffitt (1984), and Lundberg (1985) point out the same problem in static labor supply models.

${ }^{9}$ The labor supply elasticity holding the marginal utility of wealth constant, or the Frisch elasticity, is the usual object of interest in intertemporal labor supply studies. Changes in the marginal utility of wealth are potentially correlated with wage changes. Assuming away precautionary behavior and potential liquidity constraints, Browning, Deaton, and Irish (1985) and MaCurdy (1985) both show that anticipated wage changes should not be correlated with the marginal utility of wealth.

${ }^{10}$ This result relies on the assumption that the log wage increases linearly in log hours. However, Barzel (1973) speculates that, at very long work weeks, an increase in hours might lower wages as exhaustion reduces productivity, and so $w^{\prime \prime}\left(\log h_{i t}\right)<0$. In an earlier version of this article, we showed that $\left(d \log h_{i t}\right) /\left.\left(d \log W_{i t}\right)\right|_{\lambda_{i t}}$ is a downward biased estimator of $\sigma$ if $w^{\prime \prime}\left(\log h_{i t}\right)<0$. Nevertheless, the existence of tied-wage hours offers need not necessarily lead to inconsistent estimates of $\sigma$. It is nonlinearity in the wage-hours relationship that causes inconsistent estimates of $\sigma$. 
There are three objects on the right-hand side of equation (11), reflecting three different labor supply incentives from a tax change. The first term arises from changes in the post-tax wage, holding the pre-tax wage fixed. A reduction in taxes causes an increase in the post-tax wage, which, in turn, affects labor supply. This is the usual object of interest in intertemporal labor supply studies. The second term arises from the effect of hours worked on the wage. If $\sigma>0$, reductions in taxes cause increases in hours worked, which, in turn, increases the pre-tax wage (because of tied wagehours offers). Because the pre-tax wage increases, hours worked increases further. The final term is the effect of the tax change on the marginal utility of wealth. Assuming that $d \log \lambda_{i t} /\left[d \log \left(1-\tau_{t}\right)\right]=0$, we can rearrange equation (11) as

$$
\left.\frac{d \log h_{i t}}{d \log \left(1-\tau_{t}\right)}\right|_{\lambda_{i t}}=\frac{\sigma}{1-\sigma \theta} .
$$

Comparing equations (10) and (12) shows that the labor supply response to a $1 \%$ increase in $1-\tau_{t}$ is larger than the labor supply response to a $1 \%$ wage increase.

This result is important for two reasons. First, the empirical strategy for estimating labor supply elasticities becomes material. Specifically, studies that use tax changes (e.g., Eissa and Liebman 1996) to proxy for wage changes should find larger labor supply elasticities than studies that use wage changes (e.g., MaCurdy 1981; Browning et al. 1985; Altonji 1986) if wages depend on hours worked. Second, analysts who use labor supply elasticities are usually interested in the labor supply response to tax and technology changes. Labor supply elasticity estimates obtained using wage changes will be smaller than the elasticity of interest.

\section{Empirical Strategy}

Our empirical strategy is fairly transparent from figure 1 . The top panel reports the change in the average number of hours worked for all working men in the Panel Study of Income Dynamics (PSID), the Health and Retirement Survey (HRS), and the March supplement and Outgoing Rotation Groups (ORG) of the Current Population Survey. These profiles are constructed using fixed-effects estimators and are computed from samples of workers age 50-70. The next section describes the data and sample restrictions in more detail.

The number of hours worked slowly begin to decline around age 55, but the biggest drops occur after age 61. For example, among PSID workers between the ages of 61 and 62, annual work hours decline $10 \%$. Hours continue to fall at ages 63 and 64, before another large 10\% drop at 65 . After age 65, hours declines are smaller in magnitude, although sample sizes are so small that wage growth is not reliably estimated. Big drops 

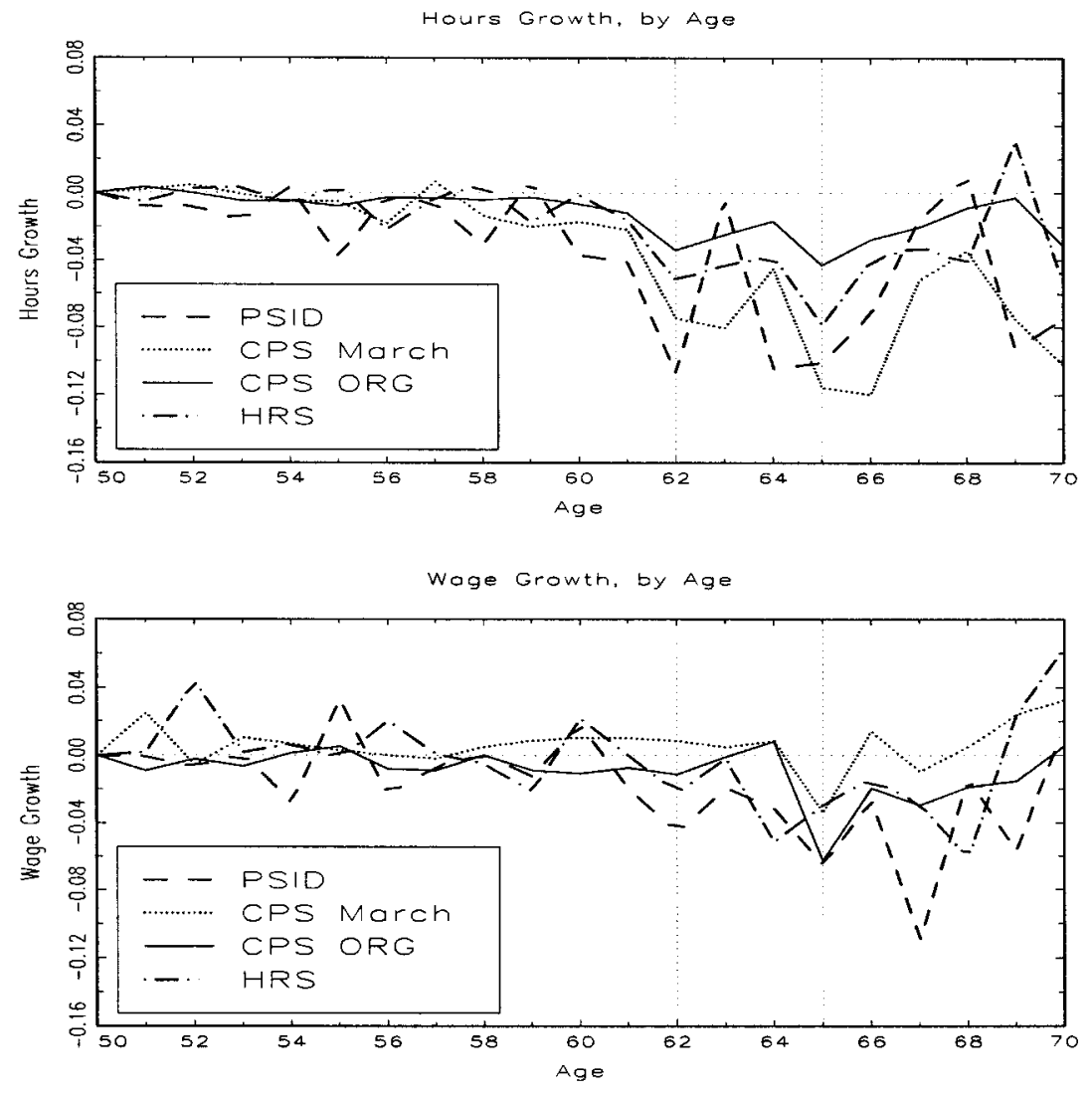

Fig. 1.- - Hours and wage growth

after age 61, particularly at ages 62 and 65 , are observed in the other three data sets as well. ${ }^{11}$

The bottom panel of figure 1 displays average wage growth for the same male workers. Wages remain relatively flat, with perhaps some modest overall decline, between ages 50 and 61. But at age 62 the average wage among PSID workers drops by $4.5 \%$. This decline continues from ages 63 through 66, with the biggest drop, $6.5 \%$, occurring at 65 . Again, these patterns are relatively consistent with those observed for the other data sets.

Taken together, the two panels in figure 1 suggest a possible causal

${ }^{11}$ The ORG shows a less severe drop in hours at ages 62 and 65 because the ORG measures changes in the work week. The other three surveys measure changes in the work year, thus accounting for both changes in the number of weeks worked and changes in the average work week. 
relationship between hours and wages. The biggest drop in wages occurs at 62 and 65 , the same ages at which the social security work disincentives begin. This suggests to us that turning age 62 and 65 are possible instrumental variables that can be used to identify the part-time/full-time wage differential.

In order to estimate a part-time differential, we use a standard instrumental variables model that allows for individual-specific fixed effects:

$$
\begin{gathered}
\log h_{i t}=f_{i}+\sum_{k=1}^{K} \gamma_{k} \operatorname{age}_{i t}^{k}+\gamma_{62} I\left\{\operatorname{age}_{i t} \geq 62\right\}+\gamma_{65} I\left\{\operatorname{age}_{i t} \geq 65\right\}+e_{i t}, \\
\log w_{i t}=z_{i}+\sum_{k=1}^{K} \delta_{k} \operatorname{age}_{i t}^{k}+\theta \widehat{\log h_{i t}}+u_{i t},
\end{gathered}
$$

where $\widehat{\log }_{i t}$ is the predicted hours level for the $i$ th individual at time $t$, using equation (13); age $_{i t}$ is the individual's age; $I\left\{\operatorname{age}_{i t} \geq 62\right\}$ and $I\left\{\right.$ age $\left._{i t} \geq 65\right\}$ are $0-1$ indicators equal to one when the individual is more than 62 and 65 years old and zero otherwise; $f_{i}$ and $z_{i}$ are individualspecific fixed effects; and the error terms $e_{i t}$ and $u_{i t}$ are white noise. ${ }^{12}$ Note that we prefer to use hours worked, rather than a part-time indicator, to avoid concerns about the ad hoc nature of a part-time/full-time threshold and because we believe that the hours measure allows us to exploit more

${ }^{12}$ The functional forms in eqq. (13) and (14) are consistent with the model described in Sec. II under the following assumptions:

$$
\begin{gathered}
\alpha_{i t}=z_{i}+\sum_{k=1}^{K} \delta_{k} \operatorname{age}_{i t}^{k}+u_{i t}, \\
\log \left(1-\tau_{t}\right)=\phi_{0}+\sum_{k=1}^{K} \phi_{k} \text { age }_{i t}^{k}+\phi_{62} I\left\{\operatorname{age}_{i t} \geq 62\right\}+\phi_{65} I\left\{\operatorname{age}_{i t} \geq 65\right\}, \\
\varepsilon_{i t}=\omega_{i 0} \sum_{k=1}^{K} \omega_{k} \operatorname{age}_{i t}^{k}+\psi_{i t},
\end{gathered}
$$

where $u_{i t}$ and $\psi_{i t}$ are white noise. The parameters in eq. (13) have the following interpretation:

$$
\begin{gathered}
\gamma_{1}=\sigma\left\{\delta_{1}+\phi_{1}+\log [\beta(1+r)]\right\}+\omega_{1}, \\
\gamma_{k}=\sigma\left(\delta_{k}+\phi_{k}\right)+\omega_{k}, \quad k=2, \ldots, K, \\
\gamma_{62}=\sigma \phi_{62}, \\
\gamma_{65}=\sigma \phi_{65}, \\
f_{i}=\sigma\left[\theta+\phi_{0}+z_{i}+\log \lambda_{i 0}\right]+\omega_{i 0}, \\
e_{i t}=\sigma\left[u_{i t}+\left(\log \lambda_{i t}-\log E_{0} \lambda_{i t}\right)\right]+\psi_{i t},
\end{gathered}
$$

where $\log \lambda_{i t}$ follows a random walk with drift term $\beta(1+r)$ (MaCurdy 1985). The drift term is captured in $\gamma_{1}$. 
informative variation..$^{13}$ However, a continuous measure of hours may introduce measurement error that biases downward our part-time wage estimate. This is a particular problem in cases where we estimate equation (13) in differenced form. Therefore, we present results that use both hours worked and the part-time dummy. In light of Hotchkiss (1991) and Ermisch and Wright (1993), we use part-time/full-time hours thresholds ranging from 30 to 38 hours per week.

Another noteworthy part of the estimating equations is the fixed-effect term. If there is an unobserved quality difference between part-time and full-time workers, cross-sectional studies of the part-time wage effect will be biased, as the part-time dummy will proxy for latent worker quality. Failure to account for the fixed effect will lead to an omitted variables bias in the cross section. Nevertheless, most studies of the part-time wage effect that we are aware of have been estimated on cross-sectional samples. ${ }^{14}$

Note that, because the fixed-effect model is identified from wage changes, composition bias problems (i.e., the question of whether highwage or low-wage individuals become part-time workers) are addressed if wage growth is the same for workers and nonworkers. However, if individuals leave the market because of a sudden wage drop, such as from job loss, we will not be able to include the new potential wage of those individuals. This problem will bias wage growth upward. Because more individuals drop out of the labor force at ages 62 and 65 than at other ages, this upward bias should be more severe at these ages. Therefore, the wage declines depicted in figure 1 understate the true wage declines at these ages, and our estimate of the part-time wage effect could be biased toward zero.

Because of the fixed effect, the specification of equations (13) and (14) is parsimonious, reflecting only essential time-varying confounding factors. One such factor is the natural aging process. Human capital theory posits that, near the end of the life cycle, workers should invest less in skill development as they have fewer years left in the labor market to recoup the investment. Therefore, wages should decline as remaining skills decline in value. Declining wages at the end of the life cycle potentially

${ }^{13}$ Hotchkiss (1991) estimates this threshold within a switching model with sample selection. She finds that the proper average hours cutoff is significantly higher, around 38 hours, than the standard 35-hour work week, and that this cutoff varies across industry. The survey used in Ermisch and Wright (1993) reports the woman's own definition of part-time. With the exception of teachers, most women's definition of part-time corresponds to less than 30 hours per work week.

${ }^{14}$ For example, Rosen (1976), Simpson (1986), Blank (1990), and Hotchkiss (1991). Ermisch and Wright (1993) use a cross-section that includes recall of work history. However, longitudinal analyses are presented in Lundberg (1985), Blank (1998), and Hirsch (2001). 
induces declining hours worked at the end of the life cycle (Heckman 1976).

To solve this problem, we assume that productivity declines smoothly with age, and so the effects of declining productivity and the declines in hours that result from declining productivity can be captured by a fourth order age polynomial. We use indicators for ages greater than 62 and greater than 65 to capture the effects of the social security system on hours and wages. These variables should capture the change in hours and wages at the exact ages of 62 and 65 .

Other potential problems with our estimation strategy are discussed in the results section.

\section{Data}

We use four data sets of workers in their fifties or sixties-the Panel Study of Income Dynamics (PSID), the outgoing rotation (ORG) of the Current Population Survey (CPS), the March supplement of the CPS, and the Health and Retirement Survey (HRS) - to deal with our concerns. Each data set has particular strengths for our purpose.

The long panel structure of the PSID is particularly useful for accounting for individual-specific attributes that might influence wages. However, the number of workers older than 61 is limited. Between 1968 and 1997, we have 11,493 person-year observations on 1,436 separate men and 4,816 person-year observations on 685 separate women. At age 62, we observe 468 men working and 163 women working. At age 65, we observe 245 men working and 76 women working. Our PSID sample, unlike those from the other surveys, does not include nonmarried women but does include nonmarried men.

Alternatively, the HRS has been following an older cohort, those age 51 to 61 in 1992, for close to a decade. After five waves of data, the last in 2000, the full panel includes 9,545 worker-year observations on 2,945 men and 9,725 worker-year observations on 2,912 women. The oldest cohort is 69 in 2000, but many of the respondents are still younger than 62 in the latest waves. Furthermore, since the survey occurs every other year, respondents' labor market activity is observed at age 62 or 65 but not both. Therefore, we only have 766 and 329 workers at ages 62 and 65 , respectively. However, the detail of the questions about work and retirement far exceeds those in the PSID.

To alleviate concerns about sample size, we used the CPS. In particular, we report results from two samples of CPS workers-those that are in the March supplements and those in the outgoing rotation groups (ORG). The CPS respondents follow a specific sampling time frame; they are surveyed for 4 months, are off for 8 months, and then are interviewed again for 4 months. Starting in 1979, respondents are in the ORG during 
the last month of each 4-month cycle. This means that all CPS respondents have two observations in the ORG, spaced 1 year apart. Since there are only two observations per person, rather than add a person-specific fixed effect to the statistical model, we work in first differences. Regardless, the ORG samples far exceed those from the PSID or HRS. We are able to match over 193,000 workers age 50-70 between 1980 and 1999, of which 7,244 are age 62 and 3,455 are age 65 during the sampling frame. The drawback to the ORG is its limited range of questions. For example, we have no information about job tenure or benefits.

A convenient compromise between the survey breadth of the HRS and the sample sizes of the ORG is the March supplement of the CPS. The March surveys include a series of questions about job characteristics, including the existence of pension plans and employer-provided health insurance. It also includes a question about how many employers the respondent has had over the last year, which allows us to denote job switchers and job stayers. Sample sizes are larger than those found in the PSID and HRS but are smaller than the ORG. Roughly 87,000 workers age 50-70 are included in the matched March samples between 1979 and 1999, of which 3,570 are age 62 and 1,841 are age $65 .{ }^{15}$ Like the ORG, we are restricted to only two observations per person. However, an important distinction between the two CPS surveys is that the ORG asks about labor market activity last week, while the March supplement describes wages and hours over the previous calendar year. These distinctions, as we shall see, can lead to different inferences.

To account for the life-cycle wage profile, all samples are restricted to workers between the ages of 50 and 70. A worker-year is included if an individual toils between 10 and 89 hours per week (or 500-4,500 hours per year) and has a real wage between $\$ 3$ and $\$ 100 .{ }^{16}$ These restrictions result in the loss of $11 \%, 45 \%, 13 \%$, and $5 \%$ of workers age $50-70$ in our PSID, HRS, March CPS, and ORG samples, respectively. ${ }^{17}$

The appendix reports descriptive statistics for the key variables in our analysis. Means in the PSID, particularly for the real hourly wage, are

${ }^{15}$ However, the 1985-86 and 1995-96 March files cannot be matched. See app. S of Unicon Research Corporation (1999).

${ }^{16}$ In the CPS, we also discard workers with more than a $400 \%$ wage change across years. This affects a small minority of respondents and has very little impact on the results.

${ }^{17}$ The difference between samples that exclude $4 \%$ or $5 \%$ vs. over $10 \%$ is due to when part-year workers (who work over 10 hours per week) are dropped. For work-related questions based on last week's activity (ORG and HRS), many partyear workers are excluded since they would have zero hours at the survey date. For questions based on last year's activity (March CPS and PSID), we drop workers who work fewer than 500 hours per year. Therefore, part-year workers in the March CPS and PSID might be excluded due to our hours restrictions. 
different from those of the other surveys because of the greater composition of men.

\section{Results}

Table 1 reports the basic instrumental variables results. Each panel displays the first-stage estimates for the age 62 and age 65 instruments $\left(\gamma_{62}\right.$ and $\gamma_{65}$ in eq. [13]) and the second-stage (eq. [14]) parameter of interest, $\theta$, the part-time wage effect. All regressions also include a fourth-order age polynomial and year or survey dummies. ${ }^{18}$ The results are reported separately for men and women. The top panel reports findings when $h_{i t}$ is a continuous measure of hours. Alternatively, the bottom panel shows how robust these results are to a commonly used discrete measure of part-time status, whether the individual worked more than 35 hours per week or 1,750 hours per year. ${ }^{19}$ All standard errors are Huber-White and corrected to account for multiple observations within individuals.

As already shown in figure 1, table 1 shows the high degree of association between the age 62 and age 65 indicators and our measures of hours worked. For men, hours drop at least an additional $2 \%$ per year, and in some instances as much as $10 \%$, at these older ages, relative to what is expected based on the fourth-order age polynomial. Furthermore, $t$-statistics usually exceed 3 for each of the age instruments, suggesting that these drops are not only economically but also statistically important. For women, the change in hours at ages 62 and 65 is not as striking. With the exception of the PSID, hours drop by roughly $1 \%-2 \%$ above what would be expected by the age polynomial, with mixed statistical importance.

The row labeled "predicted hours change" shows our estimate of the causal impact of hours on wages. For men, the point estimates are fairly stable across three of the four data sets, clustered tightly between 0.40 and 0.50 for all but the ORG and statistically significant at the $10 \%$ level for all but the HRS. Furthermore, when using the discrete hours threshold, the results remain relatively similar and, in all cases, are different from zero at standard significance levels. ${ }^{20}$

However, for women, the evidence is less clear. Part-time coefficients are statistically significant only when using the ORG, suggesting that the causal impact of hours on wages for female workers is quite weak. While

${ }^{18}$ Both the Schwarz and Akaike information criterion, described in Judge et al. (1985), suggest either a second- or a third-order polynomial.

${ }^{19}$ The results are not sensitive to using other reasonable cutoffs, such as 30 or 38 hours per week.

${ }^{20}$ When we estimate the wage-hours relationship with fixed effects using OLS, the point estimates are of the wrong sign and statistically significant. This is not a surprise, as a number of studies have found that OLS is biased downward in the presence of measurement error. We discuss this issue in more detail below. 
Table 1

Basic Fixed-Effects Instrumental Variables Estimates

\begin{tabular}{|c|c|c|c|c|c|c|c|c|}
\hline & \multicolumn{2}{|c|}{ PSID } & \multicolumn{2}{|c|}{ HRS } & \multicolumn{2}{|c|}{ CPS March } & \multicolumn{2}{|c|}{ CPS ORG } \\
\hline & Males & Females & Males & Females & Males & Females & Males & Females \\
\hline \multirow{2}{*}{\multicolumn{9}{|c|}{$\begin{array}{l}\text { A. Using continuous hours measure: } \\
\text { First stage-point estimates for instruments used in } \\
\text { hours regression: }\end{array}$}} \\
\hline & & & & & & & & \\
\hline Worker is age 62 & $\begin{array}{c}-.082 \\
(.021)\end{array}$ & $\begin{array}{c}-.046 \\
(.033)\end{array}$ & $\begin{array}{c}-.043 \\
(.015)\end{array}$ & $\begin{array}{c}-.041 \\
(.015)\end{array}$ & $\begin{array}{c}-.035 \\
(.007)\end{array}$ & $\begin{array}{c}-.015 \\
(.009)\end{array}$ & $\begin{array}{c}-.021 \\
(.004)\end{array}$ & $\begin{array}{r}-.023 \\
(.005)\end{array}$ \\
\hline Worker is age 65 & $\begin{array}{r}-.097 \\
(.031)\end{array}$ & $\begin{array}{r}-.082 \\
(.046)\end{array}$ & $\begin{array}{r}-.076 \\
(.026)\end{array}$ & $\begin{array}{l}.002 \\
.029)\end{array}$ & $\begin{array}{r}-.055 \\
(.010)\end{array}$ & $\begin{array}{r}-.026 \\
(.012)\end{array}$ & $\begin{array}{r}-.027 \\
(.006)\end{array}$ & $\begin{array}{r}-.014 \\
(.007)\end{array}$ \\
\hline Second stage—hours effect from wage regression $(\theta)$ : & $\begin{array}{l}.517 \\
(.304)\end{array}$ & $\begin{array}{l}.863 \\
.748)\end{array}$ & $\begin{array}{l}.371 \\
(.313)\end{array}$ & $\begin{array}{c}.024 \\
(.315)\end{array}$ & $\begin{array}{c}.424 \\
(.224)\end{array}$ & $\begin{array}{l}.176 \\
(.492)\end{array}$ & $\begin{array}{c}.949 \\
(.362)\end{array}$ & $\begin{array}{c}.663 \\
(.386)\end{array}$ \\
\hline \multirow{2}{*}{\multicolumn{9}{|c|}{$\begin{array}{l}\text { B. Using part-time dummy ( } 35 \text {-hour work week } \\
\text { cutoff): } \\
\text { First stage-point estimates for instruments used in } \\
\text { hours regression: }\end{array}$}} \\
\hline & & & & & & & & \\
\hline Worker is age 62 & $\begin{array}{r}-.066 \\
(.025)\end{array}$ & $\begin{array}{c}-.051 \\
(.039)\end{array}$ & $\begin{array}{r}-.030 \\
(.019)\end{array}$ & $\begin{array}{c}-.044 \\
(.021)\end{array}$ & $\begin{array}{c}-.052 \\
(.009)\end{array}$ & $\begin{array}{c}-.013 \\
(.012)\end{array}$ & $\begin{array}{r}-.018 \\
(.007)\end{array}$ & $\begin{array}{r}-.027 \\
(.008)\end{array}$ \\
\hline Worker is age 65 & $\begin{array}{c}-.095 \\
(.035)\end{array}$ & $\begin{array}{c}-.101 \\
(.049)\end{array}$ & $\begin{array}{c}-.077 \\
(.030)\end{array}$ & $\begin{array}{c}.021 \\
(.038)\end{array}$ & $\begin{array}{c}-.097 \\
(.012)\end{array}$ & $\begin{array}{c}-.061 \\
(.016)\end{array}$ & $\begin{array}{l}-.033 \\
(.009)\end{array}$ & $\begin{array}{r}-.034 \\
(.011)\end{array}$ \\
\hline Second stage—hours effect from wage regression $(\theta)$ : & .612 & .678 & .498 & -.012 & .282 & -.007 & 1.127 & .691 \\
\hline Sample size & $11,493^{(.369)}$ & $4,816^{(.606)}$ & $9,545^{(.35 /)}$ & $9,725^{(.280)}$ & $49,590^{(.130)}$ & $37,618^{(.239)}$ & $104,485^{(.429)}$ & $89,200^{(.306)}$ \\
\hline
\end{tabular}

This content downloaded from 128.041.061.139 on August 11, 2016 07:41:31 AM

All use subject to University of Chicago Press Terms and Conditions (http://www.journals.uchicago.edu/t-and-c). 
the PSID estimate is large, precision is poor. Combined with the nonexistent effects arising from the HRS and CPS March data, we conclude that there is little evidence for a causal impact of hours on wages for women, given the available data.

It is interesting to note that the ORG appears to be an outlier among both genders. We believe that this is due to differences in the period being examined. In the ORG, respondents are asked about work activity in the last week. For the other three surveys, respondents are asked about their experience in the last year. ${ }^{21}$ Rosen (1976) also finds a larger effect when using hours last week than when using hours last year. He speculates that many individuals working fewer than 1,750 hours per year are not parttime workers but rather full-time workers who are only working part of the year. Therefore, "part-time" workers using the last year measure are actually a mixture of part-time and full-time workers using the last week measure. An alternative explanation is that the last year query could bias our results toward zero since the survey mixes hours and wage measures across ages (e.g., the age 62 indicator is actually a combination of a year when the respondent is 61 and 62). In fact, when we run the March CPS regressions but use respondents in the outgoing rotation months (thus allowing us to use the last week variables), the point estimates are very similar to those reported for the ORG, albeit with much less precision. We take this as evidence that the 0.4 estimates for men are perhaps a lower bound of the true relationship between hours and wages.

We also attempted two variations on the instrument choice. First, we added an interaction between age 65 and whether the individual had employer-provided health insurance at age 64. Many individuals with employer-provided health insurance will lose their health insurance if they leave their job or cut their work hours. Upon eligibility for medicare at age 65 , an individual's health insurance is no longer tied to full-time job status. Therefore, this interaction takes advantage of variation in hours associated with the advent of medicare at age 65 for those who rely on employer-provided health insurance prior to 65 . However, the presence of employer-provided health insurance could be a proxy for the quality of a job and therefore be an invalid instrument. Nevertheless, the results are virtually identical to those reported in table 1 . Second, we interact the age instruments with indicators for changes in the social security earnings test in 1990 and 1996. These specifications were run on the CPS, the only data set that had sufficient samples during the different policy years. But again, the results were virtually identical to those reported in table 1.

Still, there may be alternative explanations for why wages decline at ages 62 and 65. First, within a job, the work week is often fixed. Therefore,

${ }^{21}$ The HRS hours measure is hours worked last week multiplied by weeks usually worked per year. 
much of the variation used to identify hours changes could come from job switchers. Ruhm (1990) finds that many older workers switch to parttime bridge jobs, potentially in a different industry than their career job. Therefore, wage changes could be due to productivity changes that may result from the loss of industry-, firm-, or job-specific human capital.

We address this issue by restricting the sample to workers who have not switched employers in the last year. ${ }^{22}$ Therefore, identification is based on within-employer variation in hours worked. For the CPS, this meant throwing out any worker-year observation that involved an employer change. ${ }^{23}$ For the HRS and PSID, we control for employer changes by including a full set of employer dummy variables that separately identifies hours and wages changes that are coming from employer switches and from nonswitches. ${ }^{24}$

Table 2 reports the results of such an exercise using the men from the PSID, HRS, and March CPS. The results generally confirm our earlier findings. When we limit identification to men who stay at their employers, point estimates remain in the 0.40 range, relatively similar to those reported in table 1. Given the smaller sample sizes, standard errors rise, causing statistical significance to be severely affected in some cases. But, given how stable our estimates appear to be across data sets, we believe that larger samples would show that the part-time effect survives this test.

Alternatively, we can control for changes in industry and occupation to account for any loss of firm- and industry-specific human capital. While this is a less satisfactory way to deal with this problem, it is another robustness check of the importance of latent changes in a worker's endowments. The results appear robust to such controls. For example, rees-

${ }^{22}$ The March CPS supplement asks respondents to self-report how many employers they had during the previous year, where multiple part-time employers are counted as one employer. We define an employer switch as having more than one employer over the year. The HRS definition is based on a similar question. The PSID asks how long the individual has been with the current employer. If the individual has been with that employer less than 1 year, we consider him or her to have taken a new employer.

${ }^{23}$ This could result in not enough variation to identify the part-time effect. If this were the case, standard errors would blow up. However, while the amount of hours variation within employers is obviously smaller, it is hardly inconsequential. Among male CPS respondents between ages 50 and 70, the mean log change in annual hours worked for employer stayers and employer switchers is -0.018 and -0.075 . Among 62- and 65-year-olds, the mean hours change for an employer stayer is roughly half of that for an employer changer.

${ }^{24}$ An alternative strategy is to analyze a group of workers who were displaced involuntarily at older ages and returned to the labor market. Any wage loss that might result from another employer switch would likely have occurred after their initial displacement. However, displacement rates for older workers are low, and those that are displaced often do not return to the labor force. Therefore, such an analysis is not feasible on standard data sets, such as the Displaced Worker Survey. 
Table 2

Robustness Checks: Males Only

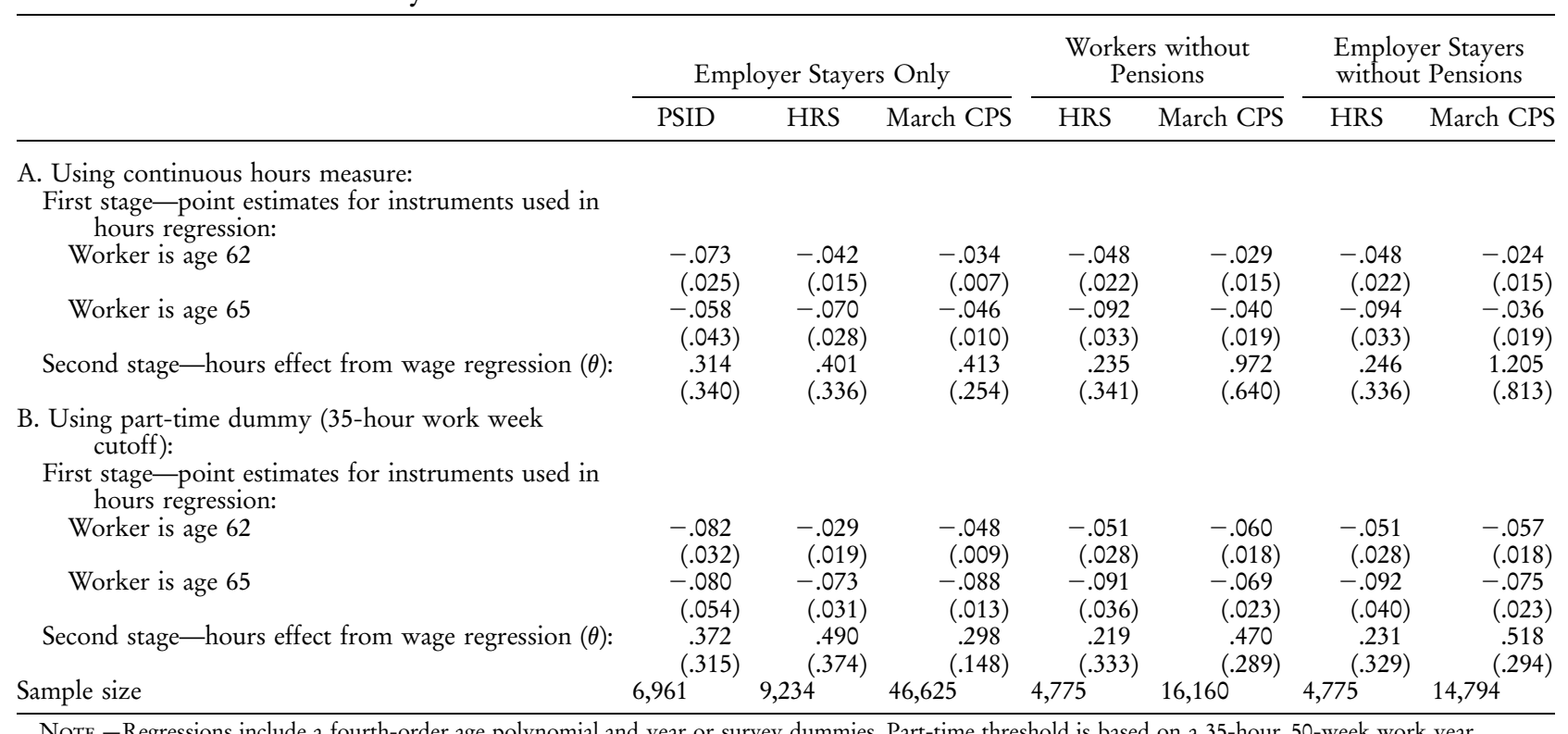


timating the CPS outgoing rotation group regressions for men but including controls for changes in occupation and industry alters our point estimates (and standard errors) from 0.95 (0.36) to 0.85 (0.39). Likewise, among CPS March respondents, occupation and industry controls change our estimates from $0.42(0.22)$ to $0.48(0.22)$. Stratifying the sample to exclude industry and occupation switchers also has no discernible effect.

A second concern about the estimation procedure is that firms may structure their compensation and pension plans in order to encourage workers to leave by age 62 or 65. Lazear (1981) implies that employers offer below-productivity compensation when a worker is young but reward him or her with above-productivity compensation at the end of his or her career. This large payday when old motivates young workers to work hard. However, this scheme potentially causes the worker to remain with the firm longer than is optimal. In order to induce the worker to leave, firms often offer low pension accrual to employees in their sixties (Gustman et al. 1998). This induces workers to leave their old, high-wage job for new jobs with potentially lower wages. Therefore, there may be a drop in wages at ages 62 and 65 because workers are moving to jobs with lower wages, not because they are working fewer hours.

To sidestep this problem, we look at samples of workers who do not have pension plans. Moreover, our results on workers who remain at the same firm should inform us about the severity of this problem. The second panel of columns in table 2 shows the results on a restricted sample of male workers without pension plans. With the HRS, we restrict the sample to those without defined benefit plans. For the March CPS, we restrict the sample to those without any pension plan. Naturally, this increases the standard errors. Still our inferences, while less assured, are similar in nature. The final panel of columns in table 2 combines the job stayers and pension restrictions. Again, although precision is hampered by the small sample size, we see little reason to recast inferences based on these results. Clearly, we are less confident of our findings, but this is likely due to a lack of older workers who are not switching jobs and do not have pension plans rather than any instability in the parameter estimates.

A third consideration is the presence of measurement error. Because variation in measured hours and wage changes is dominated by measurement error (Altonji 1986; Bound, Brown, and Mathiowetz 2001), measurement error is of particular concern in studies of the interrelation between hours and wages. This problem is especially severe because the wage is constructed by dividing earnings by hours, meaning that measurement error in wages and hours is negatively correlated by construction. This causes the OLS estimate to be biased downward, and is a similar problem to the "division bias" problem in the labor supply literature. Because we use age to instrument for wage and hours changes, our instrument should be uncorrelated with measurement error in hours and 
wage changes at the population level. Although age is uncorrelated with measurement error at the population level, age will in general be correlated with measurement error in the small sample (Nelson and Startz 1990; Staiger and Stock 1997).

To address the small sample bias problem, we vary our sample sizes and reestimate the part-time wage effect on the smaller sample using a "jackknife" procedure (Efron 1982). If the small sample bias problem is unimportant, then reducing the sample size should make our estimates less precise, but it should not affect the point estimates in any predictable way. However, if small sample bias is important, reducing the sample size should bias results toward the OLS estimate (Nelson and Startz 1990).

We ran our two-stage regressions 1,000 times each on random samples of 10,000, 20,000, and 30,000 March CPS men between the ages of 50 and 70 . Over the 1,000 repetitions, a random sample of 10,000 men results in a part-time penalty point estimate that averages 0.41 but has a standard deviation around that average of 1.09 . The impact of doubling the sample to 20,000 is to alter the point estimates ever so slightly, to 0.43 , but substantially reduce the standard deviation around the point estimate to 0.33 . Finally, when the sample is raised to 30,000 men, the average coefficient is again barely affected (0.43), but the standard deviation drops to 0.20 . This pattern is consistent with that seen across data sets with varying sample sizes, as well as the sample restrictions reported in table 2. Point estimates remain remarkably stable, although precision can be seriously hindered by small samples, suggesting that small sample bias is relatively unimportant.

A final concern is that compensation packages change with age. At older ages, workers may demand nonpecuniary benefits at the cost of lower wages. While it is important to note that one of these key benefits, reduced hours, is precisely the parameter that we are trying to identify, other forms of compensation are not included in our wage measure.

We attempt to control for this problem by inferring the value of employer-provided health insurance and pensions using the March CPS and HRS, the only two data sets that have information on whether respondents earn these benefits. ${ }^{25}$ Since these data sets do not report the dollar value of benefits, we infer their value using average employer-paid health plan costs reported in EBRI (1999, tables 3.3 and 4.2) and age-specific pension

\footnotetext{
${ }^{25}$ According to the the Bureau of Labor Statistics's annual Employer Costs for Employee Compensation release, our measure of wages, which should include paid leave and bonuses, makes up $82 \%$ of total compensation. Health insurance and retirement savings encompass another $6 \%$ and $3.5 \%$, respectively. The remaining $8.5 \%$ of compensation consists almost entirely of legally required benefits that should not vary much in our sample.
} 
Table 3

Basic Fixed-Effects Instrumental Variables Estimates, Using Compensation Measures: Males Only

\begin{tabular}{lcc}
\hline & HRS & March CPS \\
\hline $\begin{array}{l}\text { A. Using continuous hours measure, second stage, } \\
\text { hours effect from wage regression }(\theta)\end{array}$ & .533 & .421 \\
$\begin{array}{l}\text { B. Using part-time dummy (35-hour work week cutoff), } \\
\text { second stage, hours effect from wage regression }(\theta)\end{array}$ & $(.337)$ & $.222)$ \\
Sample size & .725 & $(.424)$ \\
\hline
\end{tabular}

Note.-Compensation includes wages, pensions, and health insurance. See the text for details.

accrual values from Gustman et al. (1998). ${ }^{26}$ Table 3 reports results using this more complete compensation measure. For both the CPS and HRS, the results are similar to those reported in table 1. Using the hours measure, elasticity point estimates continue to be around 0.40 . Therefore, we believe that offsetting nonwage compensation is unlikely to be significantly biasing our results.

Furthermore, while changes in other latent nonmonetary benefits, such as a less stressful workplace or more flexible schedule, are potentially problematic, many of our results suggest that this is unlikely to explain the main results. First, inclusion of an age polynomial will account for compensation mix choices that change smoothly with age. While it is still plausible that there are discrete changes in nonpecuniary benefits at ages 62 and 65 , we believe that our specification somewhat limits this concern. Second, including industry and occupation dummies, which made very little difference to our results, may eliminate obvious career changes that would be consistent with the nonpecuniary benefits story. Finally, our results are robust to restricting the sample to job stayers. Again, this does not eliminate the possibility that workers are trading wages for nonpecuniary benefits even within firms, but the robustness of the results to these checks suggests to us that our results are consistent with the existence of a part-time wage penalty for older men.

\section{Conclusion}

This article assesses the impact of wage-hours ties on intertemporal labor supply elasticity. We present new empirical evidence on wage-hours ties among older workers that takes advantage of the work disincentives of the social security system. Using this identification strategy, we find evidence that male part-time workers earn lower wages than male full-

${ }^{26}$ Because we lack data on employer-provided health plan costs by demographic group, each person with a plan is assigned the average cost, as computed by the Employee Benefit Research Instititute (EBRI). However, pension values are agespecific. 
Table 4

The Labor Supply Response to a Change in Taxes under Different Assumptions about the Labor Supply Responses to a Change in Wages and the Tied Wage-Hours Effect

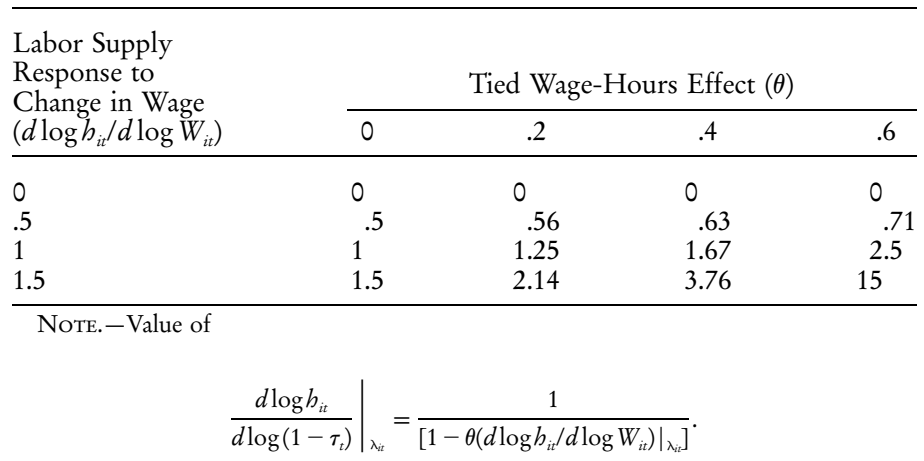

time workers, although there is little evidence of such an effect among women. Depending on the specification and the data employed, our estimates imply that cutting older mens' hours from 40 to 20 hours per week lowers wages by up to $25 \%$.

Not accounting for such a relationship leads to an underestimate of the effect of tax changes on the posttax wage and consequently labor supply. Table 4 quantifies this effect. In particular, equation (12) shows the relationship between the labor supply response to changes in taxes (or equivalently, technology), $\left.\left[d \log h_{i t} / d \log \left(1-\tau_{t}\right)\right]\right|_{\lambda_{i t}}$, the labor supply response to changes in the wage, $\left.\left(d \log h_{i t} / d \log W_{i t}\right)\right|_{\lambda_{i t}}=\sigma$, and the tied wage-hours coefficient $\theta$. Recall that most studies measure $\left.\left(d \log h_{i t} / d \log W_{i t}\right)\right|_{\lambda_{i t}}$ and find the variable to be usually between 0 and 0.5 for continuously employed men but often greater than 1 for women (e.g., Heckman and MaCurdy 1980). Most of our estimates of the tied wage-hours coefficient $\theta$ are in the neighborhood of 0.4. Assuming that $\left.\left(d \log h_{i t} / d \log W_{i t}\right)\right|_{\lambda_{i t}}=.5$ and $\theta=.4$, equation (12) shows that the labor supply response to a technology change is $26 \%$ greater ( 0.5 vs. 0.63 ) than the labor supply response to a wage change for men. However, using an estimate of the wage elasticity of 1 for women, the difference could be substantial, perhaps a $67 \%$ difference (1 vs. 1.67), although it is important to note that we find very weak evidence of any wage-hours tie for women. Of course, our estimates are based on older cohorts of workers and therefore may not be representative of a wage-hours tie for prime-age workers. Nevertheless, if older workers are representative of the population, it suggests that the interrelationship between hours and the wage is economically important to labor supply estimation. 


\section{Appendix}

Table A1

Descriptive Statistics

\begin{tabular}{|c|c|c|c|c|}
\hline & \multirow[b]{2}{*}{ PSID } & \multirow[b]{2}{*}{ HRS } & \multicolumn{2}{|c|}{ CPS } \\
\hline & & & March & ORG \\
\hline \multicolumn{5}{|c|}{ Hours (average): } \\
\hline Ages $50-70$ & 1,941 & 1,981 & 2,000 & 39.4 \\
\hline Age 62 & 1,835 & 1,842 & 1,896 & 38.0 \\
\hline Age 65 & 1,611 & 1,625 & 1,738 & 35.0 \\
\hline \multicolumn{5}{|c|}{ Part-time dummy (average): } \\
\hline Ages 50-70 & .303 & .199 & .205 & .205 \\
\hline Age 62 & .372 & .282 & .280 & .245 \\
\hline Age 65 & .560 & .398 & .412 & .377 \\
\hline \multicolumn{5}{|c|}{ Real hourly wage (average in 1996 dollars): } \\
\hline Ages $50-70$ & 17.26 & 16.07 & 16.08 & 14.93 \\
\hline Age 62 & 16.55 & 15.26 & 15.29 & 14.39 \\
\hline Age 65 & 15.26 & 13.46 & 14.74 & 12.64 \\
\hline \multicolumn{5}{|l|}{ Male (average): } \\
\hline Ages $50-70$ & .705 & .516 & .568 & .543 \\
\hline Age 62 & .741 & .535 & .576 & .536 \\
\hline Age 65 & .704 & .567 & .557 & .528 \\
\hline \multicolumn{5}{|l|}{ Sample size: } \\
\hline Ages 50-70 & 16,309 & 19,270 & 87,208 & 193,685 \\
\hline Age 62 & 631 & 766 & 3,570 & 7,244 \\
\hline Age 65 & 321 & 329 & 1,841 & 3,455 \\
\hline Years covered & $1969-96$ & $1992-2000$ & 1979-99 & 1979-99 \\
\hline
\end{tabular}

\section{References}

Altonji, Joseph. 1986. Intertemporal substitution in labor supply: Evidence from microdata. Lournal of Political Economy 94 (June): S176-S215.

Barzel, Yoram. 1973. The determination of daily hours and wages. Ouarterlv Iournal of Economics 87 (May): 220-38.

Blank, Rebecca. 1990. Are part-time jobs bad jobs? In A future of lousy jobs? The changing structure of U.S. wages, ed. Gary Burtless, pp. 123-55. Washington, DC: Brookings Institution.

. 1998. Labor dynamics and part-time work. In Research in labor economics, vol. 17, ed. Solomon Polachek, pp. 57-93. Stamford, CT: JAI.

Bound, John, Charles Brown, and Nancy Mathiowetz. 2001. Measurement error in survey data. In Handbook of econometrics, vol. 5, ed. James Heckman and Ed Leamer, pp. 3705-3843. Amsterdam: NorthHolland.

Browning, Martin, Angus Deaton, and Margaret Irish. 1985. A profitable approach to labor supply and commodity demands over the life-cycle. Econometrica 53 (May): 503-43.

EBRI (Employee Benefit Research Institute). 1999. EBRI bealth benefits databook. Washington, DC: EBRI-ERF. 
Efron, Bradley. 1982. The jacknife, the bootstrap, and other resampling plans. Philadelphia: Society for Industrial and Applied Mathematics.

Eissa, Nada, and Jeffery Liebman. 1996. Labor supply response to the earned income tax credit. Quarterly Iournal of Economics 111 (May): 605-37.

Ermisch, John, and Robert Wright. 1993. Wage offers and full-time and part-time employment by British women. Iournal of Human Resources 28 (Winter): 111-33.

French, Eric. 2000. The effects of health, wealth, and wages on labor supply and retirement behavior. Working Paper no. 00-2, Federal Reserve Bank of Chicago.

Gustman, Alan, Olivia Mitchell, Andrew Samwick, and Thomas Steinmeier. 1998. Evaluating pension entitlements. Unpublished manuscript, Dartmouth College.

Heckman, James. 1976. A life-cycle model of earnings, learning, and consumption. Lournal of Political Economv 84 (August): S11-S44.

Heckman, James, and Thomas MaCurdy. 1980. A life cycle model of female labour supply. Review of Economic Studies 47 (January): 47-74.

Hirsch, Barry. 2001. Why do part-time workers earn less? The role of worker and job skills. Unpublished manuscript, Trinity College, San Antonio, TX.

Hotchkiss, Julie. 1991. The definition of part-time employment: A switching regression model with unknown sample selection. International Economic Review 32 (November): 899-917.

Judge, George, W. E. Griffiths, R. Carter Hill, Helmut Kutkepohl, and Tsoung-Chao Lee. 1985. The theory and practice of econometrics. New York: Wiley \& Sons.

Lazear, Edward. 1981. Agency, earnings profiles, productivity, and hours constraints. American Economic Review 71 (September): 606-20.

Lundberg, Shelly. 1985. Tied wage-hours offers and the endogeneity of wages. Reviere of Economics and Statistics 67 (August): 405-10.

MaCurdy, Thomas. 1981. An empirical model of labor supply in a lifecycle setting. Iournal of Political Economy 89 (December): 1059-85.

- 1985. Interpreting empirical models of labor supply in an intertemporal framework with uncertainty. In Longitudinal analysis of labor market data, ed. James Heckman and Burton Singer. Cambridge: Cambridge University Press.

Moffitt, Robert. 1984. The estimation of a joint wages-hours labor supply model. Lournal of Labor Economics 2 (October): 550-66.

Nelson, Charles, and Richard Startz. 1990. Some further results on the exact small sample properties of the instrumental variables estimator. Econometrica 58 (July): 967-76.

Rosen, Harvey. 1976. Taxes in a labor supply model with joint wageshours determination. Econometrica 44 (May): 485-507.

Ruhm, Christopher. 1990. Bridge jobs and partial retirement. Lournal of Labor Economics 8 (October): 482-501.

Simpson, Wayne. 1986. Analysis of part-time pay in Canada. Canadian Lournal of Economics 19 (November): 798-807. 
Staiger, Douglas, and James Stock. 1997. Instrumental variables with weak instruments. Econometrica 65 (May): 557-86.

Unicon Research Corporation. 1999. Current Population Survey: March data dictionary. College Station, TX: Stata. 